\title{
Impact of a health educational interventional program on reducing the head lice infestation among pupils in an elementary school of a sub- tropical region
}

\section{Mohsen Najjari}

Mashhad University of Medical Sciences Ghaem Hospital

Mohammad Amin Gorouhi

Kerman University of Medical Sciences

Hossein Zarrinfar ( $\square$ h.zarrin@gmail.com )

Mashhad University of Medical Sciences https://orcid.org/0000-0002-1449-4668

Bibi Razieh Hosseini Farash

Mashhad University of Medical Sciences

Jamshid Jamali

Mashhad University of Medical Sciences

Elham Moghaddas

Mashhad University of Medical Sciences

Mohammad Ebrahimipuor

Kerman University of Medical Sciences

\section{Research}

Keywords: Pediculosis, Training programs, Primary schools, Infestation, Iran

Posted Date: April 5th, 2021

DOI: https://doi.org/10.21203/rs.3.rs-386348/v1

License: (c) (i) This work is licensed under a Creative Commons Attribution 4.0 International License. Read Full License 


\section{Abstract \\ Background}

Pediculosis is an important social challenge that can be caused by human head louse, Pediculus humanus capitis. This infestation is cosmopolitan, especially in countries with low hygiene and sanitation. Regular health education classes for students and their parents are required to reducing this infestation in schools and families. This study aimed to evaluate the impact of a health education intervention program on reducing of head lice among pupils of an elementary school.

\section{Methods}

In a case-control study, a total of 594 pupils, a girl elementary school, were screened for pediculosis (2015-2016). Interventions were applied in two steps, pediculosis cases eradication and training-oriented prevention program. Visual inspection was applied for initial diagnosis of infection. The suspected cases were confirmed by wood lamp examination and potassium hydroxide $(\mathrm{KOH})$ microscopic wet-mount examination. An elementary school in the same area was selected as the control group, with no interference. The prevalence of contamination by the same method was obtained in the study group.

\section{Results}

At the beginning of study, the overall prevalence of pediculosis among pupils was $8.4 \%(49 / 594)$. The mean age in all pupils was $9.86 \pm 1.83$ years old and the most infestation was showed in fourth-grade students with 10 years old. Analysis of statistics demonstrated a significance difference between having infestation and the number of members in the families. The interventions led to a significant increase of parenting knowledge on prevention program of pediculosis ( $p$-value $<0.001)$, and a decreased prevalence of pediculosis in pupils to $3 \%(8 / 594)$ ( $p$-value $<0.05)$.

\section{Conclusions}

The prevalence of pediculosis was significantly reduced following the interventions in the school. The applied interventions may be implemented in other residual centers to get rid of this important infestation.

\section{Background}

Head lice infestation is an important social challenge, which can be developed by Pediculus humanus capitis as a human head louse. This infestation is cosmopolitan, especially in countries with low hygiene and sanitation [1]. These obligate ectoparasites of human have been well-known antiquity and are associated with some life-threatening diseases including epidemic typhus, relapsing fever, and trench 
fever [2]. As a rapid spreading infestation, pediculosis is considered the most common contagious disease among school children afterward common cold virus [3]. Spreading of lice is more commonly due to direct contact with the hair of infested people. However, other uncommon routes such as contact with clothing and inanimate objects and personal belongings of infested persons are reported throughout the world [4]. Living in more crowded places including schools, orphanages, and other residual centers increase the risk of infestation. Subsequently, infested people in the mentioned centers spread lice between their families as well as societies [5]. However, parents' education level, family financial status and geographical location of the schools have been found to have no association with the spreading of head lice [6]. On the other hand, head lice infestation has been more reported in females than males [7]. Untreated pediculosis can result in itching, hives, repeated wounding of head and body skin, mental health (nightmares), and allergy in infested individuals [3, 8]. These mentioned symptoms are more common in chronically infected patients, and it is due to toxicity of the insect saliva [9]. Head lice outbreaks and its obvious symptoms are more occurred in children and pre-school pupils and lead to a negative attitude by their classmates and friends [10]. Due to the potential spreading of pediculosis from infested people to society and their families, treatment and follow up of head lice infestations should be more emphasized in each region [11]. For some people, the pediculosis management and treatment is expensive and laborious. Thus, it should be considered as a community-based approach to cover families, schools, health care professionals and the governments $[12,13]$.

Previous studies in Iran demonstrated a considerable prevalence of head lice infestation in all provinces or geographic regions [14-21]. This infestation is increased significantly over time in both girls and boys, and it was varied from $1.72 \%$ in $2014-2015$ to $3.42 \%$ in $2017-2018$ [22, 23]. Effective communication between parents and school health instructors about head lice can has an essential role in the control of pediculosis. Regular health education classes for students and their parents are required to reducing this infestation in schools and families [24, 25]. Despite the efforts of health authorities in Iran, the incidence of head lice infestation is increased in school children under the age of fifteen, particularly in female elementary school pupils [20,23]. Moreover, the incidence of pediculosis is increased in Mashhad metropolis, the capital of Khorasan-Razavi Province. Due to being a hospitable city and a destination for religious tourism, this city has been a major endemic focus of pediculosis in Iran [26].

This study aimed to evaluate the effectiveness of parental knowledge and attitude on reducing of head lice among pupils in elementary schools in northeastern Iran. For this goal, a training-oriented process has been designed for increasing the awareness of teachers, pupils, and parents to prevention and control approaches of pediculosis in Mashhad city, northeastern Iran.

\section{Materials And Methods}

Study area

In a case-control study, a total of 594 school children from a girl elementary school in Mashhad city, the capital of Khorasan-Razavi Province, were screened for head lice infestation (pediculosis) between 2017 
to 2018. In a developed form, demographic data, weight, height, hair length, body mass index (BMI), parents' education and occupations, and the number of family members were recorded. Moreover, the frequency of infestation were measured for each pupil two times.

\section{Sampling and detection}

The school was randomly selected from a socio-economic medium area of Mashhad city. The sample size was determined according to the expected prevalence of pediculosis (12.5\%), which already mentioned in other articles. Using Cochran's formula (prevalence rate) and considering error of $5 \%$ and test power of $80 \%$ and relative error of $p / 4$, the minimum predictable sample size was determined about 880 cases. Which, one third was considered to the control group, and two thirds to the intervention group. The visual inspection was applied for initial diagnosis of pediculosis infection by the school's competent public health consultant. Followed by, the suspected cases were confirmed by wood lamp and direct microscopic examination. The wood lamp examination determined the existence of lice eggs (nits) in greenish-yellow fluorescents that attached to the base of the infested hair shaft. During the direct microscopy examination, hair samples were trimmed with scissors, and were clarified with a drop of $10 \%$ potassium hydroxide $(\mathrm{KOH})$ on a microscopic slide, covered with a sterile coverslip (with a maximum magnification of $100 x$ and $400 x)$.

Detected infestations in the pupils were categorized into past, recent and present infestation cases. Detecting of dead eggs and/or nits more and less than $1 \mathrm{~cm}$ from the scalp is categorized in past and recent infestation, respectively. The existence of lice and/or eggs was considered as a present infestation. The light infestation was considered in cases with less than 5 lice and a few eggs. Numerous lice and eggs was considered as heavy infestation, and the existence of lice, eggs and numerous lice eggs and nits was detected as heavy long-standing infestation [27]. An elementary school in the same area with 311 pupils was selected as the control group, without any interference. The prevalence of contamination by the same method was obtained in the study group.

Fifty parents who participated in the training sessions voluntarily, participated in the survey and asked for nine questions in a standard questionnaire, whose validity and reliability had already been confirmed by the health belief model (HBM) [28]. The subjects were the aspects of recognizing the causative agent, the outcomes of the disease, and treatment and prevention methods for pediculosis. They responded before and after the training course to assess their learning as well as their general knowledge.

Interventions

In two steps, the interventions were applied in eradication of infestation due to case detection, and training-oriented prevention program. These implementation steps were applied with considering to ethical standards about infested cases and their families. The detected cases were referred to health centers for completing the treatment courses. Simultaneously, the transmission, prevention, and control of these ectoparasites were completely explained to their parents by specialists as well. Moreover, the holding justification meetings were done for school managers and teachers to provide solutions and 
recommendations to manage this infestation. These sessions were held more particularly for classes with a high load of head lice infestation. For easy detecting of lice and their eggs and nits, related photos were showed to pupils and their parents using group discussion. Preventive healthcare strategies were described as personal hygiene including hair combing, covering the coat and jacket in nylon bags prior to placing in classroom hanger, swimming pools, mosques, hotels and even relatives' house. Moreover, for more effective learning, some brochures and educational pamphlets about pediculosis were distributed among pupils and their parents. A developed questionnaire with eight questions about diagnostic, epidemiology, treatment and preventions aspects were filled by parents before and after training, to evaluate their general knowledge and measure the effectiveness of learning.

\section{Statistical analysis}

All data were statistically analyzed using SPSS software (version 20.0, SPSS, Inc., Chicago, IL, USA). Relative frequencies were determined and data were expressed as mean \pm standard deviation (SD). Shapiro-Wilk test was used to check the normality of quantitative variables. Mann Whitney U test was used to test the null hypothesis, and the Chi-square test was used to compare the relations and means. McNemar's test was also applied to investigate the prevalence rate before and after the intervention. A p value of less than 0.05 was considered as statistically significant.

\section{Results}

\section{Before interventions}

At the beginning of study in autumn, the overall prevalence of pediculosis among the pupils was $8.4 \%$ (49/594). The mean age in all pupils was $9.86 \pm 1.83$ years old and the most infestation was showed in fourth-grade students with 10 years old (Table 1). The descriptive statistics for age, height, weight, body mass index (BMI), number of family members, and frequency of infestation in before and after course are shown in Table 2. There was no statistically significant difference between having head lice and age, weight, height, and BMI of pupils. The education level and occupation of the pupil's parents are characterized in Table 3. The number of family member's average among studied pupils was $4.30 \pm 0.93$, and the infestation frequency's average in four examinations was $1.08 \pm 0.84$. The analysis of statistics demonstrated a significance difference between having infestation and the number of family members. Moreover, the families with larger populations had more head lice infestation. The findings demonstrated a more infestation in long hairs (62\%) pupils, but without any statistically significance difference. The severity of infestation in $55 \%$ of the infested cases was light with a low number of 1-5 nits. Heavy infestations were observed in almost all grades. Figure 1 shows an instance of the presence a nit attached to the hair shaft of infected pupil in a direct microscopic examination (wet mount). 
Table 1

Infected and non-infected cases among study group according to their different educational grade.

\begin{tabular}{|llllll|}
\hline School grade (age) & Negative cases & $\begin{array}{l}\text { Positive cases } \\
(<6 \text { years })\end{array}$ & $\begin{array}{l}\text { Positive } \\
\text { cases } \\
(6-10 \text { years })\end{array}$ & $\begin{array}{l}\text { Positive } \\
\text { cases } \\
(>10 \text { years })\end{array}$ & Total \\
\hline Pre-school (6) & 59 & 2 & 0 & 2 & 63 \\
\hline Grade 1 (7) & 85 & 4 & 1 & 2 & 92 \\
\hline Grade 2 (8) & 90 & 4 & 2 & 2 & 98 \\
\hline Grade 3 (9) & 101 & 5 & 4 & 2 & 112 \\
\hline Grade 4 (10) & 103 & 8 & 3 & 1 & 115 \\
\hline Grade 5 (11) & 107 & 4 & 1 & 2 & 114 \\
\hline Total & 545 & 27 & 11 & 11 & 594 \\
\hline
\end{tabular}

Table 2

Different characteristics of pupils, before interventions for head lice infestation

\begin{tabular}{|lllll|}
\hline Characteristic & $\begin{array}{l}\text { Non-infected } \\
\text { (Mean } \pm \text { SD) }\end{array}$ & $\begin{array}{l}\text { Infected } \\
\text { (Mean } \pm \text { SD) }\end{array}$ & $\begin{array}{l}\text { Total } \\
\text { (Mean } \pm \text { SD) }\end{array}$ & $\begin{array}{l}\text { p- } \\
\text { value }\end{array}$ \\
\hline Age & $9.68 \pm 1.94$ & $10.4 \pm 1.7$ & $9.86 \pm 1.93$ & 0.44 \\
\hline Weight & $36.07 \pm 12.51$ & $34.24 \pm 12.86$ & $\begin{array}{l}35.17 \pm \\
12.65\end{array}$ & 0.44 \\
\hline Height & $138.97 \pm 12.91$ & $\begin{array}{l}137.02 \pm \\
13.87\end{array}$ & $\begin{array}{l}138.02 \pm \\
13.36\end{array}$ & 0.55 \\
\hline BMI & $18.26 \pm 4.27$ & $17.65 \pm 3.78$ & $17.96 \pm 4.03$ & 0.51 \\
\hline Number of family members & $4.06 \pm 0.78$ & $4.56 \pm 1.01$ & $4.30 \pm 0.93$ & 0.003 \\
\hline $\begin{array}{l}\text { Frequency of infestation in four time } \\
\text { hair examination }\end{array}$ & $0.00 \pm 0.00$ & $1.72 \pm 0.93$ & $1.08 \pm 0.84$ & $<$ \\
\hline
\end{tabular}


Table 3

Occupation and education level of parents of studied pupils for head lice infestation

\begin{tabular}{|c|c|c|c|c|c|}
\hline & & $\begin{array}{l}\text { Non-infested } \\
\text { (SD) }\end{array}$ & $\begin{array}{l}\text { Infested } \\
\text { (SD) }\end{array}$ & $\begin{array}{l}\text { Total } \\
\text { (SD) }\end{array}$ & $\begin{array}{l}\mathrm{p}- \\
\text { value }\end{array}$ \\
\hline \multirow[t]{4}{*}{$\begin{array}{l}\text { Father's } \\
\text { education }\end{array}$} & $\begin{array}{l}\text { Less than high school } \\
\text { diploma }\end{array}$ & $26(50 \%)$ & $15(30 \%)$ & $\begin{array}{l}41 \\
(40.2 \%)\end{array}$ & \multirow[t]{4}{*}{0.04} \\
\hline & High school diploma & 19 (36.5\%) & $19(38 \%)$ & $\begin{array}{l}38 \\
(37.3 \%)\end{array}$ & \\
\hline & University degree & $7(13.5 \%)$ & $16(32 \%)$ & $\begin{array}{l}23 \\
(22.5 \%)\end{array}$ & \\
\hline & Total & 52 & 50 & 102 & \\
\hline \multirow[t]{4}{*}{$\begin{array}{l}\text { Mother's } \\
\text { education }\end{array}$} & $\begin{array}{l}\text { Less than high school } \\
\text { diploma }\end{array}$ & $17(32.7 \%)$ & $12(24 \%)$ & $\begin{array}{l}29 \\
(28.4 \%)\end{array}$ & \multirow[t]{4}{*}{0.50} \\
\hline & High school diploma & $28(53.8 \%)$ & $28(56 \%)$ & $\begin{array}{l}56 \\
(54.9 \%)\end{array}$ & \\
\hline & University degree & $7(13.5 \%)$ & $10(20 \%)$ & $\begin{array}{l}17 \\
(16.75)\end{array}$ & \\
\hline & Total & 52 & 50 & 102 & \\
\hline \multirow[t]{4}{*}{$\begin{array}{l}\text { Father's } \\
\text { occupation }\end{array}$} & Self-employed & 40 (76.9\%) & $37(74 \%)$ & $\begin{array}{l}77 \\
(75.5 \%)\end{array}$ & \multirow[t]{4}{*}{0.93} \\
\hline & Retired/Unemployed & $3(5.8 \%)$ & $3(6 \%)$ & $6(5.9 \%)$ & \\
\hline & Employee & $9(17.3 \%)$ & $10(20 \%)$ & 19 (18.6) & \\
\hline & Total & 52 & 50 & 102 & \\
\hline \multirow{4}{*}{$\begin{array}{l}\text { Mother's } \\
\text { occupation }\end{array}$} & Self-employed & $1(1.9 \%)$ & $4(3.08 \%)$ & $5(4.9 \%)$ & \multirow[t]{4}{*}{0.44} \\
\hline & Housewife & $46(88.5 \%)$ & $41(82 \%)$ & $\begin{array}{l}87 \\
(85.3 \%)\end{array}$ & \\
\hline & Employee & $5(9.6 \%)$ & $5(10 \%)$ & $\begin{array}{l}10 \\
(9.8 \%)\end{array}$ & \\
\hline & Total & 52 & 50 & 102 & \\
\hline
\end{tabular}

After interventions

The interventions lead to decreasing of prevalence of pediculosis in pupils from $8.4 \%(49 / 594)$ to $3 \%$ (8/594). These decreasing was occurred with a statistically significance difference ( $p$-value $<0.05)$. Moreover, according to the data extracted from the questionnaires, $97 \%$ of the parents believed that the training courses were useful and effective in the raising of awareness about pediculosis. The prevalence of pediculosis in control school showed the rates of infestation $9 \%, 12 \%$, and $11 \%$ in autumn, winter, and spring, respectively. Education was able to have a significant effect of attitude of parents on 8 different 
designed questions in the field of diagnosis, epidemiology, treatment and prevention of pediculosis. Table 4 shows the results of interventions about head lice infestation among the parents of pupils.

Table 4

The results of interventions about head lice infestation among the parents of pupils, before and after interventions

\begin{tabular}{|c|c|c|c|c|c|c|}
\hline \multirow[t]{3}{*}{ Questionnaire variables } & \multirow[t]{3}{*}{ Scope } & \multicolumn{2}{|c|}{$\begin{array}{l}\text { Before } \\
\text { intervention } \\
(n=50)\end{array}$} & \multicolumn{2}{|c|}{$\begin{array}{l}\text { After } \\
\text { intervention } \\
(n=50)\end{array}$} & \multirow[t]{3}{*}{$\begin{array}{l}\text { p- } \\
\text { value* }\end{array}$} \\
\hline & & NO & Yes & No & Yes & \\
\hline & & $\begin{array}{l}\text { No. } \\
\text { (\%) }\end{array}$ & $\begin{array}{l}\text { No. } \\
\text { (\%) }\end{array}$ & $\begin{array}{l}\text { No. } \\
\text { (\%) }\end{array}$ & $\begin{array}{l}\text { No. } \\
\text { (\%) }\end{array}$ & \\
\hline Checking your child hair for infestation & Diagnosis & $\begin{array}{l}32 \\
(65)\end{array}$ & $\begin{array}{l}18 \\
(35)\end{array}$ & $\begin{array}{l}8 \\
(15)\end{array}$ & $\begin{array}{l}42 \\
(85)\end{array}$ & \\
\hline $\begin{array}{l}\text { Knowledge about transmission routes of } \\
\text { pediculosis }\end{array}$ & Epidemiology & $\begin{array}{l}43 \\
(86)\end{array}$ & $\begin{array}{l}7 \\
(14)\end{array}$ & $\begin{array}{l}5 \\
(10)\end{array}$ & $\begin{array}{l}45 \\
(90)\end{array}$ & 0.774 \\
\hline Using personal accessory & Prevention & $\begin{array}{l}44 \\
(88)\end{array}$ & $\begin{array}{l}6 \\
(12)\end{array}$ & $\begin{array}{l}10 \\
(20)\end{array}$ & $\begin{array}{l}40 \\
(80)\end{array}$ & 0.454 \\
\hline $\begin{array}{l}\text { Ironing yours and your child's clothes } \\
\text { regularly }\end{array}$ & Prevention & $\begin{array}{l}32 \\
(65)\end{array}$ & $\begin{array}{l}18 \\
(35)\end{array}$ & $\begin{array}{l}10 \\
(20)\end{array}$ & $\begin{array}{l}40 \\
(80)\end{array}$ & 0.186 \\
\hline Knowledge about treatment of pediculosis & Treatment & $\begin{array}{l}27 \\
(55)\end{array}$ & $\begin{array}{l}23 \\
(45)\end{array}$ & $\begin{array}{l}3 \\
(5)\end{array}$ & $\begin{array}{l}47 \\
(95)\end{array}$ & $\begin{array}{l}< \\
0.001\end{array}$ \\
\hline $\begin{array}{l}\text { Participate in educational programs at } \\
\text { school about pediculosis prevention }\end{array}$ & Prevention & $\begin{array}{l}47 \\
(95)\end{array}$ & $\begin{array}{l}3 \\
(5)\end{array}$ & $\begin{array}{l}3 \\
(5)\end{array}$ & $\begin{array}{l}47 \\
(95)\end{array}$ & $<0.001$ \\
\hline Use the bath weekly & Prevention & $\begin{array}{l}33 \\
(66)\end{array}$ & $\begin{array}{l}17 \\
(34)\end{array}$ & $\begin{array}{l}5 \\
(10)\end{array}$ & $\begin{array}{l}45 \\
(90)\end{array}$ & $<.001$ \\
\hline Use the common blanket and cloth & Prevention & $\begin{array}{l}23 \\
(46 \\
)^{4}\end{array}$ & $\begin{array}{l}27 \\
(54)\end{array}$ & $\begin{array}{l}11 \\
(21)\end{array}$ & $\begin{array}{l}39 \\
(79)\end{array}$ & 0.015 \\
\hline
\end{tabular}

\section{Discussion}

Despite global improvements in the hygiene and sanitation of societies, pediculosis is reported from both developed and developing countries. This is considered as a growing neglected infestation in many regions of the world, especially developing countries. Pediculosis can be occurred in schools and other residual centers of rural and urban areas (5). Furthermore, pediculosis should be distinguished specifically from superficial fungal diseases such as trichomycosis, tinea capitis, white piedra, black piedra and dandruff caused by Malassezia [29]. Interestingly in the current study we faced with several misdiagnosed cases how later rule out for pediculosis. Choosing the right treatment requires a 
prior accurate diagnosis (clinical and laboratory), because of the possibility of drug interactions and side effects. However, some physicians do empirical treatment regardless of patient referral to the laboratory for definitive diagnosis. In some cases, these infections may also be simultaneously [30]. Hence, in such cases it requires the collaboration of an entomologist/parasitologist with other specialists such as a mycologist and dermatologist.

The high prevalence (8.4\%) of pediculosis in recent study is in line with the previous studies in Iran, which demonstrated prevalence from $1.6 \%$ to $67 \%$ in different provinces $[17,19,31]$. No statistically significant difference between pediculosis and age, weight, height, and BMI of pupils. There were also no relationship between the variables in previous studies in Iran and other countries [22, 32]. However, this study showed that all pupils in schools are at risk of head lice infestation. On the other hands, it was shown that the number of individuals in the families is an effective factor on more infestation. This finding agree with the previous study in Iran with an association between mentioned variable [31]. In the line with other studies in Iran, despite more infestation in long hair pupils (62\%), no statistical difference was indicated in the current study [31,32]. Heavy and light pediculosis was demonstrated in all infested pupils in every age group. Although, the occupation and education level of parents have been showed no effect on the frequency of pediculosis [20]. According to the study results, it seems any increasing in the education level of the family members, can lead to serious changes in the attitude, viewpoint and behavior of all family members about pediculosis. However, its reasons has been not explained exactly, and needs additional clarification on the specific reasons in various studies. High prevalence of pediculosis in Mashhad elementary schools could be a reflection of the family's lifestyle changes in recent years. This problem might be related to increasing use of music player devices among them, such as earphones and headphones, which are usually shared between family's members. Moreover, other urban civilization phenomenon such as the subway, which has been more popular, can be effective as a crowded and closed place in the formation of uncontrolled outbreaks. Furthermore, the use of schools to welcome tourists and religious pilgrims in recent years on various occasions has let to temporarily accommodate large human populations in the metropolis of Mashhad. This event could be considered as a potential in creating an epidemic at the schools, particularly in summer that must be considered.

Interventions in the infested pupils and programming for the training of parents and pupils as well as teachers have critical role in the control of pediculosis in each society [33, 34]. Improvement of parent's awareness, knowledge, and perception about head lice, timely preventive health actions, and interruption of the parasite lifecycle could lead to decrease of this infestation in the present study. For example, before intervention in our study, more than $86 \%$ of parents have no knowledge about transmission routes of pediculosis. While, after the intervention, the ratio has changed significantly. Our findings are in line with studies of [28] and [35] that previously measured the level of parental learning in health education programs for pediculosis. Despite this significant decrease in the prevalence rate, the eradication was not achieved, which seems to be due to the short duration of intervention and control. Therefore, it is suggested to approve and implement some long-term 5-year plans for future projects. For example, Frankowski et al. could achieve a considerable success in this field, during a 6-year plan [11]. 
Some of the important results that we achieved in this study include: first, creating a sense of responsibility in pupils to convey and share useful about prevention of infestation among their families, relatives and classmates. Second, the parent-teacher association (PTA) and its role to solve the school problems through scientific and research methods have been regarded. Third, use of the educational potentials using families, which led not to impose financial burden on families have been noticed, country health services, and school management. Forth, to reduce of anxiety around the stressful situation for the parents and teachers, those were in daily contact with the infested pupils. No such study has ever been done on female elementary school students in that area, so the findings of this study could increase our knowledge from the epidemiological aspects and could change the authorities' attitude from expensive case therapy toward cheap group training No such study has ever been done on female elementary school students in that area, so the findings of this study could increase our knowledge from the epidemiological aspects and could change the authorities' attitude from expensive case therapy

toward cheap group training No such study has ever been done on female elementary school students in that area, so the findings of this study could increase our knowledge from the epidemiological aspects and could change the authorities' attitude from expensive case therapy toward cheap group training One of the notable points in this regard, there have not been ever conducted such studies on female elementary school students in this area. So, the findings of this study could increase our knowledge from the epidemiological aspects of disease, and could change the authorities' attitude and focus from expensive case therapy toward cheap group training.

\section{Conclusion}

This study provided the evidence-based effective interventions for reducing head lice infestation in the elementary schools. Current study showed a successful practical approach, step by step with emphasis on process-oriented teaching to reduce pediculosis infestation using contribution of teachers, students and families. However, further studies are required to understand the effectiveness of these interventions in the control of pediculosis in other regions, due to the multiple geographical, cultural and climatic variations.

\section{Abbreviations}

KOH: potassium hydroxide, HBM: the health belief model; SD: standard deviation; BMl: body mass index

\section{Declarations}

\section{Acknowledgements}

The authors are grateful to Mashhad University of Medical Sciences Mashhad, Iran for supporting of this study.

\section{Authors' contributions}


MN contributed to the design, implementation, and writing of the manuscript. MAG, BRHF and JJ contributed to critically refining the article. EM and ME were involved in conducting the study. $\mathrm{HZ}$ (Correspondence) contributed to the data analyses. All authors read and approved the final manuscript.

\section{Funding}

This study was supported by the Vice-Chancellor for Research, Mashhad University of Medical Sciences Mashhad, Iran with project number 971950.

\section{Availability of data and materials}

The datasets used and/or analyzed during the current study are available from the corresponding author on reasonable request.

\section{Declarations Ethics approval and consent to participate}

This study was approved by the Ethics Committee of Mashhad University of Medical Sciences, Mashhad, Iran, according to the Ethics Committee code of IR.MUMS.fm.REC.1398.347.

\section{Consent for publication}

Not applicable.

\section{Competing interests}

The authors have no conflicts of interest.

\section{References}

1. Pollack RJ, Engelman D, Steer AC, Norton SA. Ectoparasites. International Encyclopedia of Public Health2016. p. 417-28.

2. Houhamdi L, Parola P, Raoult D. Lice and lice-borne diseases in humans. Medecine tropicale: revue du Corps de sante colonial. 2005;65(1):13.

3. Hensel P. The challenge of choosing a pediculicide. Public Health Nursing. 2000;17(4):300-4.

4. Mumcuoglu KY. Prevention and treatment of head lice in children. Pediatric Drugs. 1999;1(3):211-8.

5. Byrne JP. Encyclopedia of Pestilence, Pandemics, and Plagues: AM: ABC-CLIO; 2008.

6. Lidonde R. Scaling up school sanitation and hygiene promotion and gender concerns. School Sanitation \& Hygiene Education. 2004:40.

7. Slonka GF, Fleissner ML, Berlin J, Puleo J, Harrod EK, Schultz MG. An epidemic of Pediculosis capitis. The Journal of parasitology. 1977:377-83.

8. Fernández S, Fernández A, Armentia A, Pineda F. Allergy due to head lice (Pediculus humanus capitis). Allergy. 2006;61(11):1372. 
9. Scott P, Middlefell L, Fabbroni G, Mitchell D. Interesting case: cervical lymphadenopathy, induced by head lice. British Journal of Oral and Maxillofacial Surgery. 2005;43(6):515.

10. Haghi FM, Golchin M, Yousefi M, Hosseini M, Parsi B. Prevalence of pediculosis and associated risk factors in the girls primary school in Azadshahr City, Golestan Province, 2012-2013. Iranian Journal of Health Sciences. 2014;2(2):63-8.

11. Frankowski BL, Weiner LB, Health CoS, Diseases Col. Head lice. Pediatrics. 2002;110(3):638-43.

12. Kool B, Thomas D, Moore D, Anderson A, Bennetts $P$, Earp K, et al. Innovation and effectiveness: changing the scope of school nurses in New Zealand secondary schools. Australian and New Zealand journal of public health. 2008;32(2):177-80.

13. Willems S, Lapeere H, Haedens N, Pasteels I, Naeyaert J-M, De Maeseneer J. The importance of socio-economic status and individual characteristics on the prevalence of head lice in schoolchildren. European Journal of Dermatology. 2005;15(5):387-92.

14. Ghofleh Maramazi H, Sharififard M, Jahanifard E, Maraghi E, Mahmoodi Sourestani M, Saki Malehi A, et al. Pediculosis humanus capitis prevalence as a health problem in girl's elementary schools, Southwest of Iran (2017-2018). Journal of Research in Health Sciences. 2019;19(2).

15. Nejati J, Keyhani A, Tavakoli Kareshk A, Mahmoudvand H, Saghafipour A, Khoraminasab M, et al. Prevalence and Risk Factors of Pediculosis in Primary School Children in South West of Iran. Iran J Public Health. 2018 Dec;47(12):1923-9. PubMed PMID: 30788308. Pubmed Central PMCID: PMC6379608.

16. Raeisi S, Eteghadi A, Poodineh Z, Balouchi A. Prevalence of head lice infestation and its associated factors among primary school students in Zabol. International Journal of Pharmacy and Technology. 2016;8(3):19135-41.

17. Saghafipour A, Nejati J, Zahraei-Ramazani A, Vatandoost H, Mozaffari E, Rezaei F. Prevalence and risk factors associated with head louse (Pediculus humanus capitis) in Central Iran. International Journal of Pediatrics. 2017;5(7):5245-54.

18. Shayeghi M, Paksa A. Epidemiology of head lice infestation in primary school pupils, in khajeh city, East azerbaijan province, iran. Iranian journal of arthropod-borne diseases. 2010;4(1):42.

19. Soleimani-Ahmadi M, Jaberhashemi SA, Zare M, Sanei-Dehkordi A. Prevalence of head lice infestation and pediculicidal effect of permethrine shampoo in primary school girls in a low-income area in southeast of Iran. BMC Dermatology. 2017;17(1).

20. Tappeh KH, Chavshin A, Hajipirloo HM, Khashaveh S, Hanifian H, Bozorgomid A, et al. Pediculosis capitis among primary school children and related risk factors in Urmia, the main city of West Azarbaijan, Iran. Journal of arthropod-borne diseases. 2012;6(1):79.

21. Vahabi A, Shemshad K, Sayyadi M, Biglarian A, Vahabi B, Sayyad S, et al. Prevalence and risk factors of Pediculus (humanus) capitis (Anoplura: Pediculidae), in primary schools in Sanandaj city, Kurdistan province, Iran. Tropical Biomedicine. 2012;29(2):207-11.

22. Amirkhani MA, Alavian SM, Maesoumi H, Aminaie T, Dashti M, Ardalan G, et al. A nationwide survey of prevalence of pediculosis in children and adolescents in Iran. Iranian Red Crescent Medical 
Journal. 2011;13(3):167-70.

23. Ziaoddini A, Riahi R, Heidari-Beni M, Ziaoddini H, Zamani S. National and provincial prevalence of pediculus humanus capitis among urban students in iran from 2014 to 2018. Journal of Research in Health Sciences. 2019;19(4).

24. Benelli G, Caselli A, Di Giuseppe G, Canale A. Control of biting lice, Mallophaga - a review. Acta Tropica. 2018;177:211-9.

25. Genta FA, Diaz-Albiter HM, Salgueiro P, Gomes B. Control of vector-borne human parasitic diseases. BioMed Research International. 2016;2016.

26. Berenji F, Marvi-Moghadam N, Naghibozakerin Meibodi P. A retrospective study of ectoparasitosis in patients referred to Imam Reza Hospital of Mashhad, Iran. BioMed research international. 2014;2014.

27. Vermaak Z. Model for the control of Pediculus humanus capitis. Public Health. 1996;110(5):283-8.

28. Dehghani Tafti A, Rahaei Z, Askar Shahi M, Hakimi T. The effect of educational program on the prevention of pediculosis in primary school fifth grade students: An application of the Health Belief Model. Social Behavior Research \& Health. 2018;2(1):134-43.

29. Verma S. Superficial fungal infection: dermatophytosis, onychomycosis, tinea nigra, piedra. Fitzpatrick's dermatology in general medicine. 2007:1807-21.

30. Khatu SS, Poojary SA, Nagpur NG. Nodules on the hair: a rare case of mixed piedra. International journal of trichology. 2013;5(4):220.

31. Moosazadeh M, Afshari M, Keianian H, Nezammahalleh A, Enayati AA. Prevalence of Head Lice Infestation and Its Associated Factors among Primary School Students in Iran: A Systematic Review and Meta-analysis. Osong Public Health Res Perspect. 2015 Dec;6(6):346-56. PubMed PMID: 26835244. Pubmed Central PMCID: PMC4700766.

32. Firoozfar F, Moosa-Kazemi SH, Bahrami A, Yusuf MA, Saghafipour A, Armoon Z, et al. Head lice infestation (Pediculus humanus capitis) prevalence and its associated factors, among the kormanj tribes in North Khorasan Province. Shiraz E Medical Journal. 2019;20(4).

33. Moshki M, Zamani-Alavijeh F, Mojadam M. Efficacy of peer education for adopting preventive behaviors against head lice infestation in female elementary school students: A randomised controlled trial. PLoS ONE. 2017;12(1).

34. Siadat ZD, Shahsanaei A, Pakdel A. The effect of education on knowledge, attitude, and practice about pediculosis among the mothers of elementary school students. Journal of Isfahan Medical School. 2018;36(474):324-30.

35. Nezhadali A, Babazadeh T, Nadrian H, Allahverdipour H. Cognitive factors associated to pediculosis preventive behaviors among mothers of school-age children in Chaldoran county, Iran. Journal of Multidisciplinary Healthcare. 2020;13:19. 